\title{
ADOLESCENT IDIOPATHIC THORACIC SCOLIOSIS
}

\author{
A PROSPECTIVE TRIAL WITH AND WITHOUT BRACING DURING POSTOPERATIVE CARE
}

\author{
A. G. Christodoulou, H. G. PRince, J. K. WEBB, R. G. BURWELl
}

From the University Hospital, Nottingham

\begin{abstract}
Fifty patients with adolescent idiopathic scoliosis treated by posterior fusion and Harrington instrumentation augmented by a Cotrel bar or by sublaminal Luque wires were studied in a prospective trial to ascertain the need for postoperative bracing.

Twenty-five patients wore a plaster brace postoperatively for six months, while 25 were managed without a brace. The mean loss of correction from the first standing postoperative radiograph to one obtained two years later was 7 in the braced group, and 6.3 in the unbraced group, the difference not being statistically significant. We conclude that postoperative bracing is unnecessary after augmented Harrington instrumentation.
\end{abstract}

Treatment of idiopathic scoliosis by posterior bony fusion was first described by Hibbs in 1924. The technique has been modified subsequently by two innovations, the use of autograft bone and the improved technique of posterior spinal fusion described by Moe (1958). The next advance was the introduction of the Harrington instrumentation (1962). More recently two methods have been used to augment correction, namely a transverse bar (Cotrel 1978) and sublaminal wires at the apex of the curve tightened around the distraction rod with a further sublaminal wire at either end to secure the hooks (Guadagni, Drummond and Breed 1984).

In the early reports of posterior fusions without instrumentation, correction of the curve was achieved postoperatively by a carefully moulded plaster brace with rest in bed for four to six months before allowing the patient to walk in a further protective brace. The papers describing the use of this method in idiopathic scoliosis reported an incidence of pseudarthrosis of $7 \%$ and a loss of correction of up to $31 \%$ (Hibbs 1924; Hibbs, Risser and Ferguson 1931; Cobb 1952; Blount et al. 1958; Moe 1958).

Harrington instrumentation has allowed the patient to be mobilised more rapidly (usually after removal of sutures) in a moulded brace which is worn for three to nine months, the duration being determined by the sur-

\footnotetext{
A. G. Christodoulou, MD, Lecturer in Orthopaedic Surgery General Hospital George Papanicolou, Thessaloniki, Greece.

H. G. Prince, FRCS. Senior Orthopaedic Registrar

J. K. Webb, FRCS, Consultant Orthopaedic Surgeon

R. G. Burwell, MD, FRCS, Professor of Human Morphology and Experimental Orthopaedics

University Hospital, Queen's Medical Centre, Clifton Boulevard, Nottingham NG7 2UH, England.

Requests for reprints should be sent to Miss H. G. Prince.

( 1987 British Editorial Society of Bone and Joint Surgery $0301620 \times / 87 / 1155 \$ 2.00$
}

geon. The pseudarthrosis rate was $4 \%$ to $5 \%$, and the loss of correction varied from 5 to 10 in the various series which have been reported (Tambornino, Armbrust and Moe 1964; Dickson and Harrington 1973; Leider, Moe and Winter 1973; Mir et al. 1975; Erwin, Dickson and Harrington 1976; Tolo and Gillespie 1981).

The brace is a physical and psychological burden to these patients, many of whom have worn one for a considerable time before operation. It occurred to us that by using Harrington instrumentation augmented either with a Cotrel bar or with sublaminal wires at the apex and at both ends, bracing after operation was probably unnecessary. In this paper we report a prospective trial to test this hypothesis.

\section{MATERIAL AND METHODS}

Fifty patients with adolescent idiopathic scoliosis having posterior spinal surgery for thoracic curves of 35 or more measured by the Cobb method (Cobb 1948) were included in our prospective trial. The surgery was performed between 1979 and 1982 and all patients were reviewed two years after operation. There were 12 males and 38 females in the group, the mean age at operation being 14 years 4 months (range 10 to 26 years). There were 42 thoracic and eight double curves; in the latter, the lumbar curve was considered to be secondary and only the thoracic curve was fused. Overall the curves ranged from 35 to 80 .

The operations were performed by one of us (JKW) or one of his senior assistants. The technique for the posterior spinal fusion was similar to that described by Moe (1958) and included decortication of spinous processes, laminae and transverse processes together with excision and fusion of facet joints. Autograft bone was harvested from the posterior iliac crest and packed into the excised 


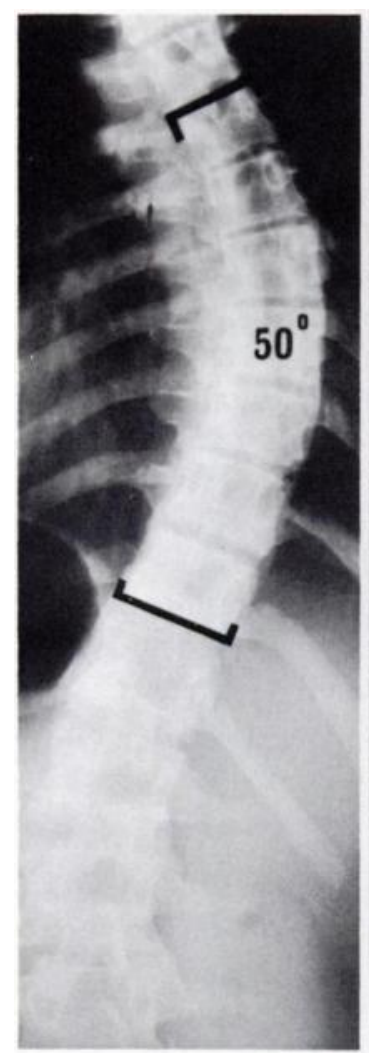

Fig. 1

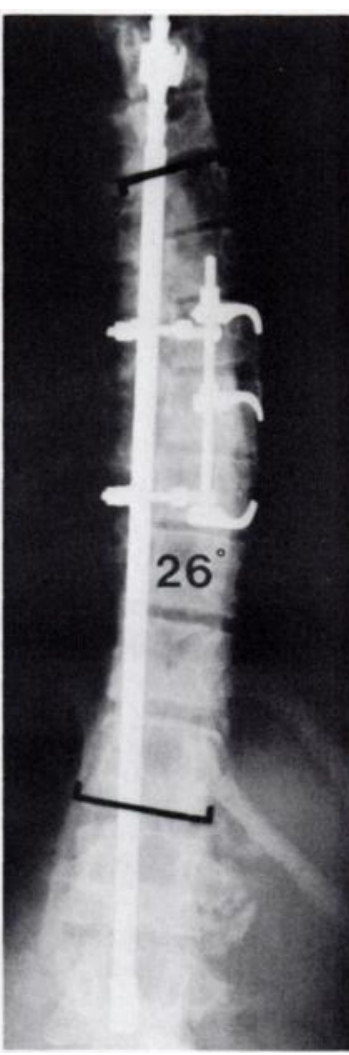

Fig. 2

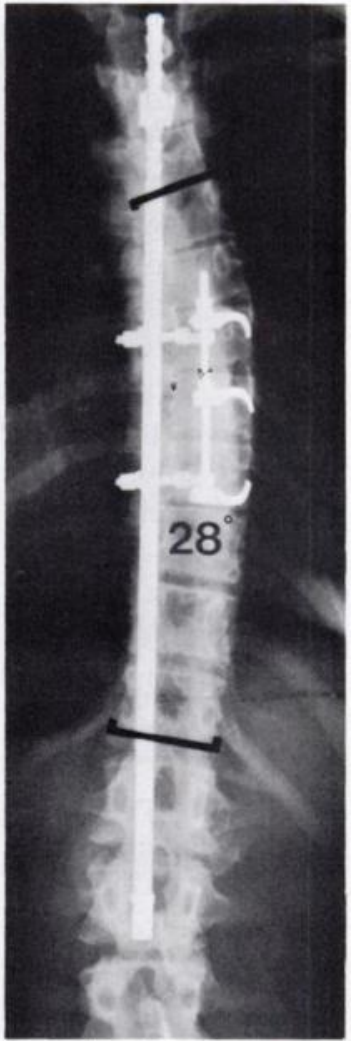

Fig. 3

Radiographs of a patient treated with bracing. Figure 1 - Pre-operatively, at the age of 14 years. Figure 2 - Two weeks after operation during bracing. Figure 3 - Two years after operation.

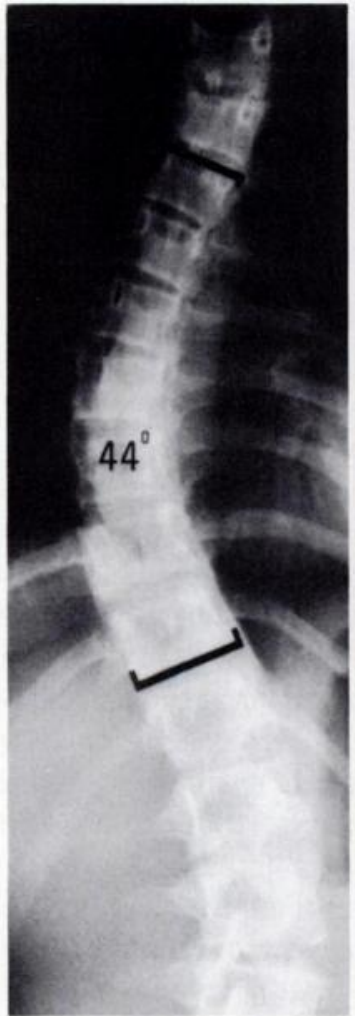

Fig. 4

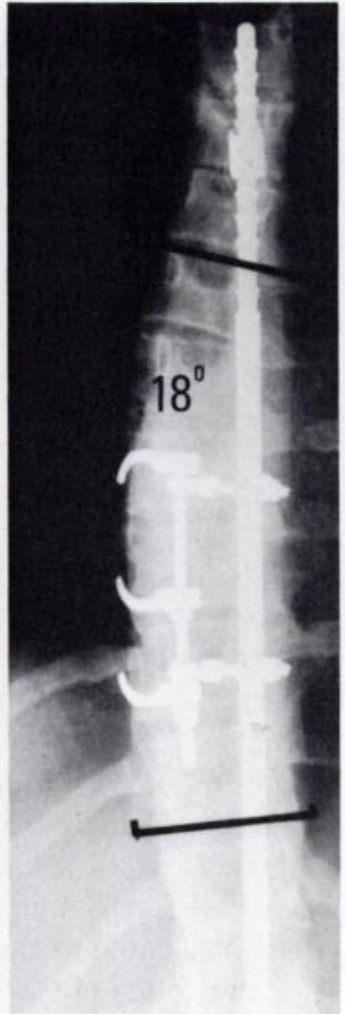

Fig. 5

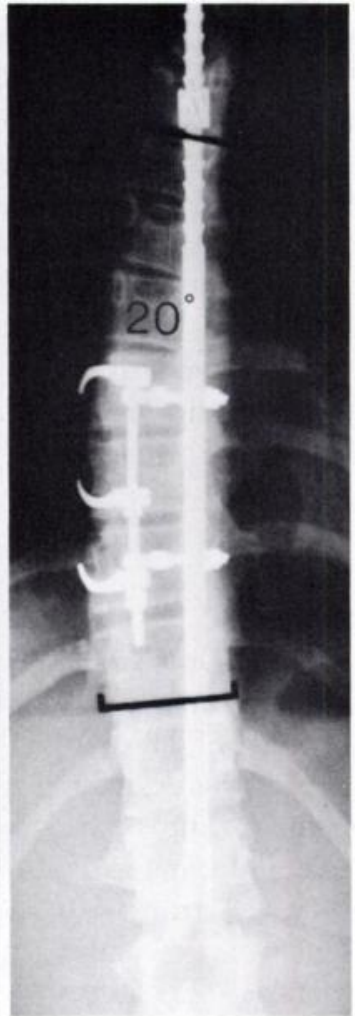

Fig. 6

Radiographs of a patient treated without bracing. Figure 4 - Pre-operatively, at the age of 12 years. Figure 5 - Two weeks after operation. Figure 6 - Two years after operation. 
facet joints and also along the rod and on the concave aspect of the spine. A square-ended Harrington distraction rod and hooks were inserted in all 50 cases, the upper hook being bifid. In 30 patients the Cotrel apparatus was added to the apical three vertebrae on the convex side and connected to the Harrington rod. One patient had a Harrington compression rod applied opposite the distraction rod because of a significant kyphosis. In the other 19 patients the Harrington distraction rods were secured by sublaminal wires at their proximal and distal levels; sublaminal wires were also placed on the concave aspect of the apical two to four vertebrae both to improve correction and to decrease rotation. The method of passing the wires was that described by Luque (1982). Spinal cord monitoring was used in all patients.

Twenty-five patients (Group I) were nursed prone in bed after operation and at seven days had their sutures removed and a plaster body cast applied. They were mobilised as soon as the plaster was dry. A spinal radiograph was taken standing and the spinal curve measured. The patient was then allowed home. A cast was worn for six months. The patient was then radiographed out of the plaster and provided there was no sign of a pseudarthrosis was allowed to mobilise free of support.

Twenty-five patients (Group II) were allowed to mobilise postoperatively as soon as it was comfortable to do so, and did not wear a brace. They went home when their wounds were healed and any raised temperature had resolved. A standing radiograph was taken before discharge from hospital.

The patients in both groups were encouraged to return to school at three weeks. Group II patients were permitted to swim three months after operation and after six months both groups were encouraged to cycle and to swim. Contact sports were not permitted for 12 months. Further radiographs were obtained at 12 months and at two years.

Figures 1 to 3 and 4 to 6 show the pre-operative radiographs and the postoperative results in two patients treated by a Harrington distraction rod and the Cotrel apparatus, one treated with a brace and the other without.

\section{RESULTS}

The Group I patients had an initial mean pre-operative spinal curve of $58^{\circ}$ (range $35^{\circ}$ to $80^{\circ}$ ), which was corrected at operation to a mean of $23^{\circ}$ (range $10^{\circ}$ to $36^{\circ}$ ). The mean curve at two years was $30^{\circ}$ (range $12^{\circ}$ to $44^{\circ}$ ). The mean correction in the Group I patients was $26.4^{\circ}$ (range 16 to $36^{\circ}$ ). The overall mean postoperative loss of correction in these curves was $7^{\circ}$ (range $2^{\circ}$ to $12^{\circ}$ ).

The Group II patients who were managed without a brace had a mean pre-operative curve angle of 54 (range $38^{\circ}$ to $72^{\circ}$ ) and the mean postoperative curve was $22.8^{\circ}$ (range $9^{\circ}$ to $42^{\circ}$ ). The radiographs at two years showed a mean curve of $29.1^{\circ}$ (range $16^{\circ}$ to $51^{\circ}$ ). The mean correc- tion at two years was $25.1^{\circ}\left(6^{\circ}\right.$ to $\left.47^{\circ}\right)$. The mean overall loss of correction in this group was $6.3^{\circ}$ (range $1^{\circ}$ to $14^{\circ}$ ) (Table I).

The largest loss of correction in both groups occurred during the first six months but there was no significant difference between the end-results (Table II). Complications were relatively minor. Two patients developed an early haematoma despite the routine use of suction drainage; their wounds were aspirated in theatre under local anaesthesia. Three patients developed superficial wound infection: prophylactic antibiotic cover was extended from the routine 48-hour period to seven days, and infection settled within 10 days. In one patient in Group I the radiograph at six months showed a dislodged Cotrel apparatus, but only $5^{\circ}$ of the initial correction had been lost and the position was stable.

The mean operating time was 2 hours 50 minutes (range 2 to 4 hours). The mean blood loss during and after operation was $900 \mathrm{ml}$ (range 700 to $1300 \mathrm{ml}$ ).

Table I. Overall results in each group

\begin{tabular}{lllll}
\hline & \multicolumn{2}{l}{ Mean curves (degrees) } & & \multicolumn{2}{l}{$\begin{array}{l}\text { Mean loss of } \\
\text { correction }\end{array}$} \\
\cline { 2 - 4 } & $\begin{array}{l}\text { Pre- } \\
\text { operative }\end{array}$ & $\begin{array}{l}\text { Post- } \\
\text { operative }\end{array}$ & At 2 years & \\
\hline $\begin{array}{l}\text { Group I } \\
\text { (braced) }\end{array}$ & 58.0 & 23.0 & 30.0 & 7.0 \\
$\begin{array}{l}\text { Group II } \\
\text { (unbraced) }\end{array}$ & 54.0 & 22.8 & 29.1 & 6.3 \\
\hline
\end{tabular}

Table II. Loss of correction during two years after operation

\begin{tabular}{llllll}
\hline & \multicolumn{3}{l}{ Mean further loss of correction (degrees) } & \\
\cline { 2 - 5 } & $\mathbf{3}$ months & 6 months & 1 year & 2 years & Total \\
\hline $\begin{array}{l}\text { Group I } \\
\text { (braced) }\end{array}$ & 3.0 & 1.6 & 1.3 & 1.1 & 7.0 \\
$\begin{array}{l}\text { Group II } \\
\text { (unbraced) }\end{array}$ & 2.9 & 2.0 & 1.0 & 0.4 & 6.3 \\
\hline
\end{tabular}

\section{DISCUSSION}

The aim of surgical treatment of idiopathic thoracic adolescent scoliosis is to achieve good correction of the spinal curve with a balanced spine and to maintain this correction until solid bony fusion has occurred. Until recently bracing has been considered an essential element of the management after such an operation.

The initial techniques described by Hibbs, Risser and Ferguson (1931), Cobb (1952) and Moe (1958) did not use internal fixation to stabilise the spine during consolidation of the bone graft, but an external support was used to achieve and maintain correction. The subsequent use of Harrington distraction rods enabled the correction to be more securely obtained and supported. More recently the supplementation of this system either with a transverse Cotrel bar on with sublaminal wires has made 
the fixation more rigid. This suggests the possibility that postoperative external bracing might be unnecessary.

Leider et al. (1973) showed a 4 loss of correction using a postoperative localiser cast. Erwin et al. (1976) showed a 5 loss in patients who wore an underarm cast for nine months. Robins, Moe and Winter (1975) described a 7 loss of correction after operation in their series of patients who wore a thoracic localiser cast for four months. Tolo and Gillespie (1981) reported an $8^{\circ}$ loss of correction in patients who were braced for six months after operation. The incidence of pseudarthrosis in these series ranged from $4 \%$ to $5 \%$. In our series no patient developed pseudarthrosis at the site of grafting. Our results, showing a mean loss of correction in each group of approximately 6 , compare well with those from other centres.

We conclude that in patients with adolescent idiopathic thoracic scoliosis undergoing surgery, an efficient technique of internal fixation with correct facet excision and bone grafting obviates the need for postoperative bracing.

The authors are grateful to Mrs J. Sycamore, SRN, and Miss H. Briggs for help with collating the patients notes and radiographs, and to Mrs S. Blythe for typing the manuscript.

\section{REFERENCES}

Blount WP, Schmidt AC, Keever ED, Leonard ET. The Milwaukee brace in the operative treatment of scoliosis. $J$ Bone Joint Surg [Am] 1958;40-A:511-25.

Cobb JR. Outline for the study of scoliosis. Am Acad Orthop Surg Instr Course Lect 1948:5:261 75.

Cobb JR. Technique, after-treatment, and results of spine fusion for scoliosis. Am Acad Orthop Surg Instr Course Lect 1952;9:65-70.
Cotrel Y. Technique nouvelles dans le traitement de la scoliose idiopathique. Int Orthop 1978; 1:247-65.

Dickson JH, Harrington PR. The evolution of the Harrington instrumentation technique in scoliosis. J Bone Joint Surg $[\mathrm{Am}]$ 1973; 55-A:993-1002.

Erwin WD, Dickson JH, Harrington PR. The postoperative management of scoliosis patients treated with Harrington instrumentation and fusion. J Bone Joint Surg [Am] 1976;58-A :479-82.

Guadagni J, Drummond D, Breed A. Improved postoperative course following modified segmental instrumentation and posterior spinal fusion for idiopathic scoliosis. J Pediat Orthop 1984;4: 405-8.

Harrington PR. Treatment of scoliosis: correction and internal fixation by spine instrumentation. J Bone Joint Surg $[\mathrm{Am}]$ 1962;44-A: 591-610.

Hibbs RA. A report of fifty-nine cases of scoliosis treated by the fusion operation. J Bone Joint Surg 1924;6:3-37.

Hibbs RA, Risser JC, Ferguson AB. Scoliosis treated by the fusion operation: an end-result study of three hundred and sixty cases. J Bone Joint Surg 1931:13:91-104.

Leider LL Jr, Moe JH, Winter RB. Early ambulation after the surgical treatment of idiopathic scoliosis. J Bone Joint Surg $[\mathrm{Am}]$ 1973; 55-A: 1003-15.

Luque ER. Segmental spinal instrumentation for correction of scoliosis. Clin Orthop 1982:163:192-8.

Mir SR, Cole JR, Lardone J, Levine DB. Early ambulation following spinal fusion and Harrington instrumentation in idiopathic scoliosis. Clin Orthop 1975; 110:54-62.

Moe JH. A critical analysis of methods of fusion for scoliosis: an evaluation of two hundred and sixty-six patients. J Bone Joint Surg 1958;40-A:529-54

Robins PR, Moe JH, Winter RB. Scoliosis in Marfan`s syndrome: its characteristics and results of treatment in thirty-five patients. J Bone Joint Surg $[\mathrm{Am}]$ 1975;57-A:358-68.

Tambornino JM, Armbrust EN, Moe JH. Harrington instrumentation in correction of scoliosis: a comparison with cast correction. $J$ Bone Joint Surg $[\mathrm{Am}]$ 1964:46-A:313 23.

Tolo V, Gillespie R. The use of shortened periods of rigid postoperative immobilization in the surgical treatment of idiopathic scoliosis: a review of sixty-four cases. J Bone Joint Surg $[\mathrm{Am}]$ 1981;63-A: 113745 . 